Article

\title{
Synthesis and Pharmacochemistry of New Pleiotropic Pyrrolyl Derivatives
}

\author{
Markella Konstantinidou, Alice Gkermani and Dimitra Hadjipavlou-Litina * \\ Department of Pharmaceutical Chemistry, School of Pharmacy, Faculty of Health Sciences, \\ Aristotle University of Thessaloniki, Thessaloniki 54124, Greece; \\ E-Mails: konsmark@hotmail.com (M.K.); germanialisa@gmail.com (A.G.) \\ * Author to whom correspondence should be addressed; E-Mail: hadjipav@pharm.auth.gr; \\ Tel.: +30-231-099-7627; Fax: +30-231-099-7679.
}

Academic Editor: Panayiotis A. Koutentis

Received: 14 July 2015 / Accepted: 3 September 2015 / Published: 10 September 2015

\begin{abstract}
Within the framework of our attempts to synthesize pleiotropic anti-inflammatory agents, we have synthesized some chalcones and their corresponding 3,4-pyrrolyl derivatives. Chalcones constitute a class of compounds with high biological impact. They are known for a number of biological activities, including anti-inflammatory and free radical scavenging activities. They inhibit several enzymes implicated in the inflammatory process, such as lipoxygenase, cyclooxygenase (COX) and lysozymes. The synthesized pyrroles have been studied for: (1) their in vitro inhibition of lipoxygenase; (2) their in vitro inhibition of COX; (3) their in vitro inhibition of lipid peroxidation; (4) their interaction with the stable, N-centered, free radical, 2,2-diphenyl-1-picrylhydrazyl (DPPH); (5) their inhibition on interleukin-6 (IL-6); (6) their anti-proteolytic activity; and (7) their in vivo anti-inflammatory activity using carrageenan-induced rat paw edema. Their physicochemical properties were determined to explain the biological results. Lipophilicity was experimentally determined. $\mathbf{2 i}$ and $\mathbf{2 v}$ were found to be promising multifunctional molecules with high antiproteolytic and anti-inflammatory activities in combination with anti-interleukin-6 activity.
\end{abstract}

Keywords: chalcones; pyrroles; pleiotropic; antioxidant; anti-lipoxygenase; anti-cyclooxygenase; anti-inflammatories 


\section{Introduction}

Inflammation is the natural response of the biological system to various stimuli. It is well established that excessive chronic inflammation is linked to reactive oxygen species and oxidative stress [1]. Moreover, chronic inflammation leads to pathological disorders, such as atherosclerosis, rheumatoid arthritis, neurogenerative diseases [2] and various types of cancer [3,4].

Upon appropriate stimulation of neutrophils, arachidonic acid is cleaved from membrane phospholipids through the enzymatic activity of phospholipase A2, and it is metabolized by two enzymes: cyclooxygenase (COX) and lipoxygenase leading to pro-inflammatory mediators, prostanoids and leukotrienes, respectively [5]. Regarding cyclooxygenases, COX-3 is the third and most recently discovered cyclooxygenase isozyme, the others being COX-1 and COX-2. COX-3 has been confirmed as an alternate splice variant of COX-1. Its activity appears to be selectively inhibited by acetaminophen and some other analgesic and antipyretic NSAIDs [6]. COX-1 is traditionally considered as a house-keeping enzyme, and it is responsible for the production of prostanoids and proinflammatory prostaglandins, implicated in homeostatic functions. COX-2 is the induced isoform, which catalyzes the production of prostaglandins during the inflammatory response [7]. The differential expression of the two isoforms, together with the fact that COX-1 is the main isoform expressed in the gastrointestinal track, led to the design and synthesis of selective COX-2 inhibitors as potent anti-inflammatory agents that would lack the gastro-intestinal side effects of traditional NSAIDs. Despite the initial success of selective COX-2 inhibitors, recent studies showed that they were associated with cardiovascular side effects, and some of them have been withdrawn from the world-wide market [8,9]. Furthermore, COX inhibition led to an increase of LOXs metabolites [10]. Hence, another strategy, which was followed towards more potent NSAIDs, was the design of dual inhibitors COX and LOX, which would have simultaneously the advantage of blocking both enzymes in the arachidonic acid cascade [11].

COX-1 and COX-2 possess distinct roles in neuroinflammation. Taking into account the differential expression of the two isoforms in central nervous system (CNS), COX-1 selective inhibition has lately emerged as a new therapeutic target for CNS inflammatory diseases [12-14].

Nowadays, there is great interest in the use of pleiotropic drugs for the treatment of complex diseases, in which more than one target is implicated. In the last decade, we have designed and synthesized several potent lipoxygenase inhibitors, antioxidants and anti-inflammatories guided by our Quantitative-Structure Activity Relationships (QSAR) results. Since inflammation is a complex phenomenon in which several different factors are implicated, pleiotropic agents will offer additional benefits. In light of this, we designed a number of 3,4-substituted pyrroles. The design principle was aimed at combining the synergistic property of biological potent chalcones to get new heterocyclic entities: pyrrolyl derivatives that might act as effective pleiotropic bioactive agents. Yet another objective of the study was to evaluate the effect of steric and electronic parameters on anti-inflammatory activities and to optimize the activity through systematic modification of the pyrrole 3,4-substituents.

Chalcones or 1,3-diaryl-2-propen-1-ones are $\alpha, \beta$-unsaturated ketones and have a large number of different biological activities. These compounds occur naturally or they are readily synthesized. In the literature, derivatives bearing the chalcone scaffold present antibacterial [15], antifungal [16], analgesic [17], anti-inflammatory [18], anticancer [19], antioxidant [20], immunosuppressive [21], gastroprotective [22], antiviral [23] and antileishmanial [24] activities. 
Pyrroles exists both in natural and synthetic products, and their ability to form chelate complexes with metals explains their significance in biological systems. Characteristic examples of tetra-pyrrole structures are heme, chlorophyll and vitamin $\mathrm{B}_{12}$. Pyrrole derivatives with various actions are reported in the literature: antimalarial [25], antimicrobial [26], anti-inflammatory [27], antioxidant [28], HIV fusion inhibitors [29], anticancer [30-32], inhibitors of dipeptidyl peptidase IV [33], selective potassium-competitive acid blockers [34] and inhibitors of HMG-CoA reductase [35]. Diarylpyrrolizines have been investigated as COX and LOX inhibitors [36]. Pyrroles with known anti-inflammatory activity, e.g., ketorolac and tolmetin, are characterized by an aroyl pyrrole moiety. A carbonyl group in the vicinal diaryl substitution is the structural feature in the design of COX-2 inhibitors. Earlier publications refer to the influence of vicinal aryl, aroyl and carbonyl unit combinations on enzyme inhibitory activity within the synthesized pyrroles [36].

From a synthetic point of view, chalcones are useful synthons for heterocyclic compounds, since the $\alpha, \beta$-unsaturated moiety can be easily exploited towards the synthesis of heterocycles with numerous reagents. With this in mind, we synthesized and used a number of chalcones, which presented antioxidant and anti-lipoxygenase activities as precursors for the synthesis of our pyrrolyl derivatives.

\section{Results and Discussion}

\subsection{Chemistry}

The synthesis of chalcones was accomplished by a Claisen-Schmidt condensation between a substituted aromatic ketone and a suitable substituted aromatic aldehyde [37], as depicted in Scheme 1. Chalcones were used as precursors for the synthesis of aryl-aroyl-substituted pyrrolyl derivatives via a van Leusen reaction [38] with tosylmethyl isocyanide (TosMIC) to give 3-aroyl-4-arylpyrroles in an intermolecular cyclization. The ring carbons C2 and C5 originate from TosMIC, whereas C3 and C4 are derived from the chalcones that act as Michael acceptors. The used chalcones present a variation of interesting preliminary anti-inflammatory biological activities and physicochemical properties, and thus, we have chosen them as promising synthons (Table 1).<smiles>O=C[IH+]</smiles><smiles>CC(=O)[AlH2]</smiles>

[a]<smiles>O=C([Al])/C=C/[Al]</smiles>

1i-vi [b]<smiles>O=C([Al])c1c[nH]cc1Br</smiles>

2i-vi

(a) $\mathrm{MeOH}, \mathrm{KOH} 15 \% w / v$, ultrasound bath, yields 57\%-78\%; (b) TosMIC, $\mathrm{NaH}, \mathrm{DMSO} / \mathrm{Et}_{2} \mathrm{O}$, ice-bath, yields $17 \%-98 \%$.

Scheme 1. Derivatives via a van Leusen reaction. 
Table 1. Chemical structures, physicochemical and reaction data of chalcones 1i-1vi.

1v [41]

" Dichloromethane.

The structural characteristics of the known synthesized chalcones, Compounds 1ii [39], 1iv [40], 1v [41], 1vi [42], were in agreement with the literature. The structure of the new 1i and 1iii compounds (with yields from 57\%-88\%) have been identified by their physicochemical and spectroscopic data. The final products were obtained in good yields $(30 \%-96 \%)$, with the only exception being Compound $2 \mathbf{i v}$, which was obtained in a lower yield (17\%). The final products were recrystallized from cold ethyl acetate. IR, ${ }^{1} \mathrm{H}-\mathrm{NMR},{ }^{13} \mathrm{C}-\mathrm{NMR}$ and elemental analysis supported the proposed structures of the synthesized pyrrolyl derivatives. The physical data of the synthesized compounds are given in detail in the Experimental Section.

\subsection{Physicochemical Studies}

\subsubsection{Determination of Lipophilicity}

Since lipophilicity is a significant physicochemical property determining the absorption, distribution, metabolism and excretion properties (ADME) of drugs, we attempted to determine experimentally the lipophilicity as $\mathrm{R}_{\mathrm{M}}$ values with reverse-phase thin layer chromatography (RPTLC) [43]. Lipophilicity was also theoretically calculated as Clog $P$ values [44,45]. According to the calculated $C \log P$ values, the most lipophilic compounds were $2 \mathrm{iii}$ (6.37) and $\mathbf{2 v}$ (6.04). However, this observation was not supported by the $\mathrm{R}_{\mathrm{M}}$ values, since Compound 2 iii presented very low lipophilicity $(-0.061)$. Furthermore, the lipophilicity of Compound $2 \mathbf{v}$ could not be determined experimentally under the reported conditions. Attempts to correlate $\mathrm{Clog} P$ and $\mathrm{R}_{\mathrm{M}}$ values failed. From our results (Table 2), it can be concluded that $\mathrm{R}_{\mathrm{M}}$ values could not be used as a successful relative measure of the overall lipophilic/hydrophilic 
properties of these molecules. Tentatively, this can be attributed to the different nature of the hydrophilic and lipophilic phases in the two systems. Clog $P$ refers to $n$-octanol/water, whereas $\mathrm{RM}_{\mathrm{M}}$ in this case refers to methanol/water. Moreover, it is likely that pyrrole derivatives form hydrogen bonds within the hydrophilic phase.

Table 2. Chemical structures, physicochemical and reaction data of pyrrole derivatives $\mathbf{2 i - 2 v i}$.

\begin{tabular}{|c|c|c|c|c|c|c|c|}
\hline No. & $A r^{1}$ & $A r^{2}$ & $C \log P$ & $\mathbf{R}_{\mathbf{M}}$ & $\mathbf{R}_{\mathbf{f}}^{\#}$ & m.p. $\left({ }^{\circ} \mathrm{C}\right)$ & Yields (\%) \\
\hline $2 \mathbf{i}$ & & & 5.90 & 0.091 & 0.7 & $165-166$ & 49 \\
\hline $2 \mathrm{ii}$ & & & 5.05 & 0.073 & 0.6 & $219-220$ & 96 \\
\hline 2iii & & & 6.37 & -0.061 & 0.9 & $233-235$ & 43 \\
\hline 2iv & & & 5.26 & -0.149 & 0.8 & $270-272$ & 17 \\
\hline $2 v$ & & & 6.04 & $\mathrm{Nd}$ & 0.9 & $285-286$ & 30 \\
\hline $2 v i$ & & & 4.07 & -0.685 & 0.7 & $247-248$ & 32 \\
\hline
\end{tabular}

Nd: not determined under these conditions; ${ }^{*}$ chloroform/ethyl acetate 2:1.

\subsubsection{Theoretical Calculation of Physicochemical Properties}

The physicochemical properties were determined with the program Spartan v.5.1.3. (Wavefunction Inc., Irvine, CA, USA) (Table 3) in the conformation of minimum energy. The values of overall molecular refractivity (CMR) and molar refractivity of substituents (MR) (Table 4) were predicted with the C-QSAR program of Biobyte [45].

Table 3. Theoretical calculation of the properties associated with energy and charge distribution for pyrrole derivatives $\mathbf{2} \mathbf{i}-\mathbf{2} \mathbf{v i}$.

\begin{tabular}{cccccccc}
\hline No. & $\boldsymbol{E}_{\text {(номо) }}(\mathbf{e V})$ & $\boldsymbol{E}_{\text {(Lumo) }}(\mathbf{e V})$ & $\boldsymbol{\Delta}_{\text {(номо-Luмо) }}(\mathbf{e V})$ & $\mathbf{S M}_{\mathbf{2}}(\mathbf{e V})$ & Elpot_min $_{(\mathbf{e V})}$ & Elpot_max $(\mathbf{e V})$ & Dipole (D) \\
\hline $\mathbf{2 i}$ & -7.95 & 2.42 & 10.37 & 2.12 & -2.16 & 3.12 & 6.06 \\
$\mathbf{2 i i}$ & -7.12 & 2.77 & 9.89 & 2.02 & -2.30 & 2.86 & 4.33 \\
$\mathbf{2 i i i}$ & -7.78 & 2.45 & 10.23 & 0.75 & -2.70 & 3.16 & 6.37 \\
$\mathbf{2 i v}$ & -7.21 & 2.41 & 9.62 & 2.53 & -2.26 & 2.95 & 4.13 \\
$\mathbf{2 v}$ & -7.29 & 2.31 & 9.6 & 2.43 & -2.13 & 3.01 & 4.99 \\
$\mathbf{2 v i}$ & -7.50 & -1.91 & 5.59 & 9.85 & -2.12 & 1.63 & 4.14 \\
\hline
\end{tabular}


Table 4. Theoretical calculation of molar refractivity, surface area and volume for pyrrole derivatives $\mathbf{2 i}-\mathbf{2} \mathbf{v i}$.

\begin{tabular}{cccccc}
\hline No & $\mathbf{C M R}$ & $\mathbf{M R}\left(\mathbf{A r} \mathbf{r}^{\mathbf{1}}\right)$ & $\mathbf{M R} \mathbf{( \mathbf { A r } ^ { \mathbf { 2 } } )}$ & Surface Area $\left(\AA^{\mathbf{2}}\right)$ & Volume $\left(\AA^{\mathbf{3}}\right)$ \\
\hline $\mathbf{2 i}$ & 9.723 & 5.250 & 2.395 & 381.77 & 376.32 \\
$\mathbf{2 i i}$ & 9.902 & 4.860 & 2.586 & 351.86 & 343.56 \\
$\mathbf{2 i i i}$ & 11.266 & 6.491 & 2.395 & 430.45 & 421.74 \\
$\mathbf{2 i v}$ & 9.328 & 4.274 & 2.586 & 345.60 & 341.68 \\
$\mathbf{2 v}$ & 10.404 & 4.274 & 3.077 & 363.97 & 359.95 \\
$\mathbf{2 v i}$ & 8.611 & 3.614 & 2.586 & 317.63 & 314.83 \\
\hline
\end{tabular}

\subsection{Biological Evaluation of Antioxidant and Anti-Inflammatory Activity}

In the present study, six new pyrrole derivatives were synthesized as pleiotropic agents against several targets implicated in inflammation. As starting materials, we used a number of promising chalcones, which have been tested as antioxidants/anti-inflammatories.

Taking into account the multifactorial character of oxidative stress and inflammation, we decided to evaluate in vitro the chalcones, as well as the pyrrolyl derivatives with regard to their antioxidant ability, as well as to their ability to inhibit enzymes implicated in the inflammation process, such as: (i) LOX; (ii) COX-2; (iii) interleukin-6 and (iv) trypsin.

Many non-steroidal anti-inflammatory drugs have been reported to act either as inhibitors of free radical production or as radical scavengers [46]. Consequently, lipid peroxidation inhibitors [47] could be expected to offer protection in inflammation and to lead to potentially effective agents.

We used several different assays to measure the antioxidant activity in vitro: (1) the interaction with the stable free radical 2,2-diphenyl-1-picrylhydrazyl (DPPH); (2) the non-enzymatic method of superoxide radical scavenging activity; and (3) the inhibition of heme-dependent lipid peroxidation of linoleic acid. The antioxidant ability of a compound should be tested in a variety of milieus to clarify the impact of factors, such as solubility or steric hindrance, which may be of overriding importance in some cases.

2,2-Diphenyl-1-picrylhydrazyl (DPPH) is a lipophilic, free, stable radical, which absorbs at $517 \mathrm{~nm}$ (violet color). Upon reduction, decolorization is observed that is stoichiometric to the number of received electrons and is representative of the antioxidant ability of compounds. The interaction/reducing activity (RA) of the examined compounds with the stable free radical DPPH is shown in Table 5. For the sake of comparison, RA \% values for nordihydroguaiaretic acid (NDGA) were included in the table. This interaction, which indicates their radical scavenging ability in an iron-free system, was measured at 100 and $1000 \mu \mathrm{M}$ after 20 and $60 \mathrm{~min}$, whereas the final concentration of DPPH was stable at $50 \mu \mathrm{M}$. With the exception of 1i and 1ii, which interact with DPPH, all of the other chalcones did not have any effect.

Considering the pyrrolyl derivatives, the results, given in Table 6, indicate no action or very low activity under these experimental conditions. It is possible that the tested compounds failed to interact with the DPPH radical owing to steric factors. Compound $2 \mathrm{ii}$ presented remarkable reducing activity at both concentrations, which was higher than that of the reference compound NDGA. Compound 2ii was additionally tested at a $10 \mu \mathrm{M}$ concentration and presented $35 \%$ and $40 \%$ interaction at 20 and $60 \mathrm{~min}$, respectively. By examining the structures of the compounds, it is likely that the antioxidant ability of Compound 2ii correlated with the presence of the double bond, a feature that is missing from any other pyrrolyl derivative. 
Table 5. Reducing ability measured as the interaction with DPPH (reducing activity \% (RA \%)); inhibition of rat paw edema induced by carrageenan (CPE \%).

\begin{tabular}{|c|c|c|c|c|c|}
\hline \multirow{2}{*}{ Comp. } & \multicolumn{2}{|c|}{ RA \% $(100 \mu \mathrm{M})$} & \multicolumn{2}{|c|}{ RA \% (1000 $\mu \mathrm{M})$} & \multirow{2}{*}{$\begin{array}{c}\text { CPE \% } \\
\text { (0.01 } \mathrm{mmol} / \mathrm{kg} \text { Body Weight) }\end{array}$} \\
\hline & $20 \mathrm{~min}$ & $60 \mathrm{~min}$ & $20 \mathrm{~min}$ & $60 \mathrm{~min}$ & \\
\hline $1 \mathbf{i}$ & 43 & 2 & 5 & na & $41^{\mathrm{c}}$ \\
\hline 1ii & 31 & 13 & 38 & 42 & $69^{d}$ \\
\hline 1iii & na & na & na & na & $86^{\mathrm{d}}$ \\
\hline 1iv & na & na & na & na & $40^{\mathrm{d}}$ \\
\hline $1 \mathbf{v}$ & na & na & na & na & $44^{\mathrm{d}}$ \\
\hline $1 \mathbf{v i}$ & na & na & na & na & $42^{c}$ \\
\hline NDGA & 81 & 83 & 96 & 96 & - \\
\hline Indomethacin & & & & & $53^{\mathrm{d}}$ \\
\hline
\end{tabular}

na: no activity under the reported experimental conditions; ${ }^{\mathrm{c}} p<0.05 ;{ }^{\mathrm{d}} p<0.01$ performed with Student's $t$-test.

Table 6. Reducing ability measured as interaction with DPPH (RA \%); superoxide radical scavenging activity $\left(\mathrm{O}_{2}{ }^{--} \%\right)$; inhibition of heme-dependent lipid peroxidation of linoleic acid (LP, IC50 values).

\begin{tabular}{|c|c|c|c|c|c|c|}
\hline \multirow{2}{*}{ Comp. } & \multicolumn{2}{|c|}{ RA \% $(100 \mu M)$} & \multicolumn{2}{|c|}{ RA \% $(1000 \mu M)$} & \multirow{2}{*}{$\begin{array}{c}\mathrm{O}_{2}^{{ }^{-}} \% \\
(100 \mu \mathrm{M})\end{array}$} & \multirow{2}{*}{$\begin{array}{c}\text { LP } \\
I_{C_{50}(\mu M)}\end{array}$} \\
\hline & $20 \mathrm{~min}$ & $60 \mathrm{~min}$ & $20 \mathrm{~min}$ & $60 \mathrm{~min}$ & & \\
\hline $2 \mathbf{i}$ & na & na & na & na & 57 & 40 \\
\hline $2 \mathrm{ii} *$ & 86 & 88 & 99 & 96 & na & na \\
\hline 2 iii & na & na & 4 & 5 & 57 & 100 \\
\hline $2 i v$ & na & na & 8 & 10 & 76 & 72 \\
\hline $2 v$ & na & na & na & na & na & 150 \\
\hline $2 \mathrm{vi}$ & na & na & na & na & 86 & na \\
\hline NDGA & 81 & 83 & 95.6 & - & - & - \\
\hline Tolmetin & 3 & 3 & 4 & 9 & - & - \\
\hline Caffeic acid & - & - & - & - & 86.1 & 6 \\
\hline
\end{tabular}

* Thirty five percent (20 $\mathrm{min}$ ) and 40\% (60 $\mathrm{min}$ ) at $10 \mu \mathrm{M}$, na: no activity under the reported experimental conditions.

Superoxide anion radical is an active form of oxygen, and it is the product of the one-electron reduction of molar oxygen. Herein, superoxide radicals were formed by mixing phenazine methosulfate (PMS) with NADH and air-oxygen. The production of radicals was estimated with the nitrobluetetrazolium method (NBT). From the tested pyrroles, Compounds $\mathbf{2 i}$ and 2 iii were equipotent (57\%) scavengers. The most active compounds were $2 \mathbf{i v}$ and 2 vi with 76 and $87 \%$, respectively. Worth noting was that derivative 2vi presented comparable activity to caffeic acid, a known reference compound. $\mathrm{Ar}^{2}$ substitution for the two most active derivatives was a phenyl group, whereas for Compound 2iv, $\mathrm{Ar}^{1}$ was a naphthyl group, and for Compound 2vi, $\mathrm{Ar}^{1}$ was an indolyl group. It should to be mentioned that Compound $\mathbf{2 v}\left(\mathrm{Ar}^{1}=\right.$ naphthyl, $\mathrm{Ar}^{2}=4$-chlorophenyl) was inactive under the reported experimental conditions. It seems that lipophilicity does not significantly influence the superoxide anion scavenging activity. In contrast, the dipole moment appeared to be important. The values of the dipole, as calculated by the program Spartan v.5.1.3. (Wavefunction Inc.), were similar for Compounds $2 \mathbf{i v}$ and 2vi (4.13 and 4.14 D, respectively), whereas for Compound $\mathbf{2 v}$, the value of the dipole was 4.99 D. Hence, the increase of dipole values correlated with a reduction in the ability of compounds to scavenge superoxide anion radicals. 
The anti-lipid peroxidation activity was determined through the inhibition of heme-dependent lipid peroxidation. The peroxidation of sodium linoleate is induced from a mixture of heme and hydrogen peroxide, which produces free radicals from the side chains of amino acids. The assay is performed at pH 7.4 with a phosphate buffer, and the products of peroxidation are identified with the thiobarbituric acid method (TBA) [48]. In particular, malonic dialdehyde, a final product of lipid peroxidation, reacts with TBA and forms a colored product, whose absorbance is measured at $535 \mathrm{~nm}$. Pyrrolyl derivatives presented moderate inhibitory activity, with the exception of $2 \mathbf{i}\left(\mathrm{IC}_{50}=40 \mu \mathrm{M}\right)$. Compounds $2 \mathbf{i i}$ and 2vi were inactive under these experimental conditions. In general, pyrrolyl derivatives were less active than the reference compound: caffeic acid. Compounds $2 \mathbf{i i}$ and 2vi with low $\mathrm{Clog} P$ values are weak inhibitors of lipid peroxidation. It seems that the increase of volume of $\mathrm{Ar}^{1}$, measured as molar refractivity $\mathrm{MR}\left(\mathrm{Ar}^{1}\right)$, enhances $\mathrm{IC}_{50}$ values and reduces the inhibitory activity (2i and $\mathbf{2} \mathbf{i i i}$; and $\mathbf{2 i i}$, $\mathbf{2 i v}$ and $\mathbf{2 v i}$ ). For derivatives $\mathbf{2 i v}$ and $\mathbf{2 v}$, the presence of an electron-acceptor, e.g., a chloro-substituent on the phenyl ring $\left(\mathrm{Ar}^{2}\right)$, diminishes the anti-lipid peroxidation activity.

Taking into account the multifactorial character of oxidative stress and inflammation, the pyrrolyl derivatives were evaluated for their anti-inflammatory activity. The following biological assays were performed in vitro: (1) inhibition of soybean lipoxygenase; (2) inhibition of COX-1; (3) inhibition of COX-2; (4) inhibition of IL-6 and (5) inhibition of the proteolytic activity of trypsin. For the anti-inflammatory in vivo assay, we used rat paw edema induced by carrageenan.

Lipoxygenase catalyzes the first two steps in the metabolism of arachidonic acid to leukotrienes. LTB4 generation is important in the pathogenesis of neutrophil-mediated inflammatory diseases [49] with a marked relation to the severity of cardiovascular diseases, asthma and cancer. We evaluated the synthesized pyrroles for their ability to inhibit soybean LOX by the UV absorbance-based enzyme assay [50]. All pyrroles presented very low or no action under these experimental conditions (Table 7). The main reason for the lack of inhibitory activity was attributed to be the bulk of molecules. We succeeded at determining the $\mathrm{IC}_{50}$ value only for Compound $\mathbf{2 i}$. The inhibition of COX-2, as a peroxidase, was determined by a colorimetric assay with the oxidation of $N, N, N^{\prime}, N^{\prime}$-tetramethyl-p-phenylenediamine (TMPD). Compounds 2iii, 2iv and 2vi were inactive under the experimental conditions (Table 7). The most potent COX-2 inhibitor at a $100 \mu \mathrm{M}$ concentration was Compound $2 \mathbf{v}\left(\mathrm{Ar}^{1}=\right.$ naphthyl, $\mathrm{Ar}^{2}=p$-chlorophenyl), followed by $\mathbf{2 i}$. The structurally-related $\mathbf{2 i v}\left(\mathrm{Ar}^{1}=\right.$ naphthyl, $\mathrm{Ar}^{2}=$ phenyl) was inactive. It is possible that electron-acceptor substituents influence the activity. Indomethacin, which was included in the study for the sake of comparison, presented $95 \%$ inhibition at $100 \mu \mathrm{M}$.

The assay used for the inhibition of IL-6 is based on an immunometric double antibody method (sandwich technique). In this assay, Compounds $\mathbf{2} \mathbf{i}$ and $\mathbf{2 v}$ were studied, which were previously proven to be the most potent COX-2 inhibitors. Both compounds gave satisfactory biological responses, both in high and in low concentrations of IL-6 (Table 8). It should to be mentioned that both compounds have been tested at $10 \mu \mathrm{M}$, a concentration significantly lower than the concentration used in the COX-2 assay. Both Compounds $2 \mathbf{i}$ and $2 \mathbf{v}$ exhibited better results compared to indomethacin.

Preliminary results (data not given) support that Compound $2 \mathbf{v}$ is a double COX-1 (75\% at concentration of $100 \mu \mathrm{M}$ ) and COX-2 inhibitor, whereas Compound 2iii is a selective COX-1 inhibitor (75\% at concentration of $100 \mu \mathrm{M})$, without any activity against COX-2. More experiments are in progress to delineate accurately the inhibition profile. 
Table 7. Inhibition of soybean lipoxygenase ( $\mathrm{LOX} \mathrm{IC}_{50} \mu \mathrm{M}$ or $\%$ at $100 \mu \mathrm{M}$ ); percent inhibition of cycloxygenase-2 (COX-2\% at $100 \mu \mathrm{M})$; inhibition of trypsin (TP IC50 $\mu \mathrm{M})$; inhibition of rat paw edema induced by carrageenan (CPE \%).

\begin{tabular}{ccccc}
\hline Comp. & $\begin{array}{c}\text { LOX IC } \\
\mathbf{5 0}(\boldsymbol{\mu M}) / \%\end{array}$ & $\begin{array}{c}\text { COX-2 \% } \\
(\mathbf{1 0 0} \boldsymbol{\mu M})\end{array}$ & $\begin{array}{c}\text { TP IC }_{\mathbf{5 0}} \\
(\boldsymbol{1 0 0} \boldsymbol{\mu M})\end{array}$ & $\begin{array}{c}\text { CPE \% (0.01 mmol/kg Body Weight) } \\
\text { or ED }_{\mathbf{5 0}} \mathbf{~ m m o l} / \mathbf{k g ~ B o d y ~ W e i g h t ~}\end{array}$ \\
\hline $\mathbf{2 i}$ & $1000 \mu \mathrm{M}$ & 67.2 & 60 & $0.061^{\mathrm{c}}$ \\
$\mathbf{2 i i}$ & $\mathrm{na}$ & 47 & $\mathrm{na}$ & $89 \%^{\mathrm{d}}$ \\
$\mathbf{2 i i i}$ & $\mathrm{na}$ & $\mathrm{na}$ & 9 & $0.0525(89 \%)^{\mathrm{c}}$ \\
$\mathbf{2 i v}$ & $10 \%$ & $\mathrm{na}$ & 65 & $0.064(75 \%)^{\mathrm{c}}$ \\
$\mathbf{2} \mathbf{v}$ & $32 \%$ & 81 & 8 & $0.063(78 \%)^{\mathrm{c}}$ \\
NDGA & $43 \mu \mathrm{M}$ & $\mathrm{nt}$ & $\mathrm{nt}$ & $\mathrm{nt}$ \\
Tolmetin & $190 \mu \mathrm{M}$ & $\mathrm{nt}$ & $\mathrm{nt}$ & $76 \%$ \\
Indomethacin & - & 95 & $\mathrm{nt}$ & $53 \%{ }^{\mathrm{d}}$ \\
Salicylic acid & - & - & 100 & $\mathrm{nt}$ \\
\hline
\end{tabular}

na: no activity under these experimental conditions, nt: not tested; ${ }^{\mathrm{c}} p<0.05 ;{ }^{\mathrm{d}} p<0.01$ performed with Student's $t$-test.

Table 8. Percent inhibition of interleukin-6 (IL-6).

\begin{tabular}{cccc}
\hline $\begin{array}{c}\text { IL-6 } \\
\mathbf{p g} / \mathbf{m L}\end{array}$ & $\begin{array}{c}\text { Comp. 2i }(\mathbf{1 0} \boldsymbol{\mu M}) \\
\text { \% Inhibition }\end{array}$ & $\begin{array}{c}\text { Comp. 2v }(\mathbf{1 0} \boldsymbol{\mu M}) \\
\text { \% Inhibition }\end{array}$ & $\begin{array}{c}\text { IMA }(\mathbf{1 0} \boldsymbol{\mu M}) \\
\text { \% Inhibition }\end{array}$ \\
\hline 1500 & 99 & 100 & 100 \\
750.0 & 98 & 99 & na \\
375.0 & 99 & 99 & na \\
187.5 & 99 & na & na \\
93.7 & na & na & na \\
46.8 & na & na & na \\
23.4 & na & na & na \\
\hline
\end{tabular}

na: no activity under these experimental conditions; IMA: indomethacin.

Trypsin is an enzyme with an active role in inflammation. Thus, we studied the anti-proteolytic ability of the pyrrole derivatives, using salicylic acid as a reference compound. Compounds $\mathbf{2} \mathbf{i}$ and $\mathbf{2 i v}$ presented $\mathrm{IC}_{50}$ values of 60 and $65 \mu \mathrm{M}$, respectively, whereas Compounds $2 \mathrm{iii}$ and $2 \mathbf{v}$ were much more potent, with $\mathrm{IC}_{50}$ values of 9 and $8 \mu \mathrm{M}$, respectively. Comparing Compounds $2 \mathbf{i v}$ and $\mathbf{2 v}$, the insertion of an electron-acceptor substituent $(\mathrm{Cl})$ on the phenyl ring (substituent $\mathrm{Ar}^{2}$ ) and the simultaneous increase of the volume of substituent $\mathrm{Ar}^{2}$ (expressed as molar refractivity) led to an enhancement of the anti-proteolytic activity.

The pyrrolyl derivatives, as well as their precursor chalcones were tested in vivo for the inhibition of rat paw edema induced by carrageenan. Chalcones 1iii and 1ii highly reduced the rat paw edema at $0.01 \mathrm{mmol} / \mathrm{kg}$ body weight, whereas $1 \mathbf{i}, \mathbf{1 i v}, \mathbf{1 v}$ and $1 \mathbf{v i}$ presented lower and almost equal response. It should to be noted that the most potent chalcones 1ii and 1iii are the precursors of the two most active pyrrolyl derivatives. All pyrrolyl derivatives at $0.01 \mathrm{mmol} / \mathrm{kg}$ body weight showed anti-inflammatory activity comparable or higher than indomethacin, which was the reference compound, and tolmetin, which was included in the study as a pyrrolyl NSAID compound. Compound 2ii showed an inhibition of $89 \%$. The two naphthyl-substituted derivatives $\mathbf{2 i v}$ and $\mathbf{2 v}$ presented almost equivalent inhibition 
( $75 \%$ and $78 \%$, respectively), indicating that the bulky substituents significantly influence the biological activity. For Compounds $\mathbf{2} \mathbf{i}, \mathbf{2} \mathbf{i i i}, \mathbf{2} \mathbf{i v}$ and $\mathbf{2 v}$, we determined their ED50 values. Considering these results, 2iii with $\mathrm{ED}_{50}=0.052 \mathrm{mmol} / \mathrm{kg}$ body weight was the most potent anti-inflammatory agent. The finding supports the primary idea of this design. Two mono-substituted pyrroles (Scheme 2), 2-benzoylpyrrole and 3-benzoylpyrrole, which, at a dose of $0.44 \mathrm{mmol} / \mathrm{kg}$, showed $34 \%$ and $43 \%$ inhibition of carrageenan-induced rat paw edema, respectively, were previously studied for their ability to inhibit carrageenan-induced edema [51].

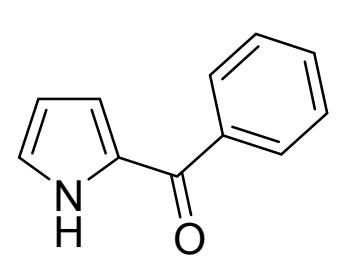

2-benzoylpyrrole

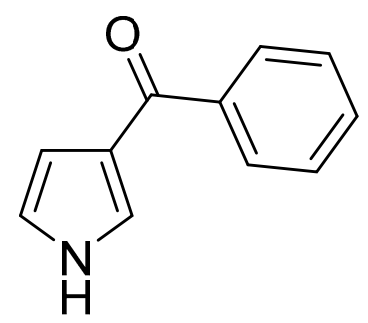

3-benzoylpyrrole

Scheme 2. Structures of mono-substituted pyrrole derivatives.

The insertion of the substituent in position 3 rather than 2 favors the inhibitory activity. Although the role of the physicochemical properties is not entirely clear for the biological results, a comparison of in vitro and in vivo results underlines a correlation between them and, in particular, among the results from the inhibition of COX-2, trypsin, IL-6 and antioxidant activity. Comparing the data from mono- and bis-substituted pyrrolyl derivatives, a second bulky substituent in position 4 significantly improved the anti-inflammatory activity in vivo. The absence of a free carboxylic group in the synthesized derivatives is considered to be important owing to its implication in adverse side effects. Such adverse side effects may occur with "classic" non-steroid anti-inflammatory drugs, in which tolmetin belongs.

\section{Experimental Section}

\subsection{Materials and Instruments}

All chemicals, solvents, chemical and biochemical reagents were of analytical grade and purchased from commercial sources (Merck, Merck KGaA, Darmstadt, Germany, Fluka Sigma-Aldrich Laborchemikalien GmbH, Hannover, Germany, Alfa Aesar, Karlsruhe, Germany and Sigma, St. Louis, MO, USA).

For the biological assays, soybean lipoxygenase, pancreatic bovine trypsin, sodium linoleate, free radical DPPH, PMS, NADH, nitroblue tetrazolium, caffeic acid, heme, $\mathrm{H}_{2} \mathrm{O}_{2}$, trichloroacetic acid, acetic acid, salicylic acid (SA), nordihydroguaiaretic acid (NDGA), $N, N, N^{\prime}, N^{\prime}$-tetramethyl- $p$-phenylenediamine (TMPD) and arachidonic acid were obtained from Sigma Chemical, Co. (St. Louis, MO, USA). Carrageenan, type K, was commercially available. Cycloxygenase-2 (COX-2) and interleukin-6 (IL-6) EIA Kit, Item No. 583371 were purchased from Cayman. Trolox was obtained from Aldrich Chemical Co. (Milwaukee, WI, USA). All starting materials were obtained from commercial sources, and they were used without further purification. 
Melting points (uncorrected) were determined on an MEL-Temp II (Lab Devices, Holliston, MA, USA). For the in vitro tests, UV-VIS spectra were obtained on a Perkin-Elmer 554 double-beam spectrophotometer (Perkin-Elmer Corporation Ltd., Lane Beaconsfield, Bucks, UK). Infrared spectra (film as Nujol mulls or $\mathrm{KBr}$ pellets) were recorded with a Perkin-Elmer 597 spectrophotometer (Perkin-Elmer Corporation Ltd.). The ${ }^{1} \mathrm{H}-\mathrm{NMR}$ spectra were recorded at $300 \mathrm{MHz}$ on a Bruker AM-300 spectrometer (Bruker Analytische Messtechnik $\mathrm{GmbH}$, Rheinstetten, Germany) in $\mathrm{CDCl}_{3}$ or DMSO using tetramethylsilane as an internal standard, unless otherwise stated. ${ }^{13} \mathrm{C}-\mathrm{NMR}$ spectra were obtained at $75.5 \mathrm{MHz}$ on a Bruker $\mathrm{AM}-300$ spectrometer in $\mathrm{CDCl}_{3}$ or DMSO solutions with tetramethylsilane as the internal reference, unless otherwise stated. Chemical shifts are expressed in $\delta$ (ppm) and coupling constants $J$ in Hz. Mass spectra were determined on a LC-MS 2010 EV Shimadzu (Shimadzu Scientific Instruments, Inc., Columbia, MA, USA), using $\mathrm{MeOH}$ as a solvent. Elemental analyses for $\mathrm{C}$ and $\mathrm{H}$ gave values acceptably close to the theoretical values $( \pm 0.4 \%)$ in a Perkin-Elmer $240 \mathrm{~B} C H \mathrm{C}$ analyzer (Perkin-Elmer Corporation Ltd.). Reactions were monitored by thin layer chromatography on 5554 $\mathrm{F}_{254}$ silica gel/TLC cards, Merck and Fluka Chemie GmbH Buchs, Steinheim, Switzerland. For preparative thin layer chromatography (PLC), silica gel $60 \mathrm{~F}_{254}$, plates $2 \mathrm{~mm}$, Merck KGaA ICH078057, were used. For the experimental determination of the lipophilicity reverse phase thin layer chromatography (RPTLC), TLC-silica gel $60 \mathrm{~F}_{254}$ DC Kieselgel, Merck $(20 \times 20 \mathrm{~cm})$ plates were used.

\subsection{Chemistry General Procedure}

\subsubsection{Chemistry General Procedure for Chalcones}

A modified Claisen-Schmidt condensation was followed. Equimolar amounts of a suitable substituted acetophenone $(10 \mathrm{mmol})$ and of a suitable substituted aromatic aldehyde $(10 \mathrm{mmol})$ were used. Each reagent was dissolved in methanol, and the total volume of the used solvent was $20 \mathrm{~mL}$. The methanolic solution of the substituted acetophenone was slowly added under stirring in the methanolic solution of the aldehyde, followed by the addition of $5 \mathrm{~mL}$ of potassium hydroxide $(15 \% w / v)$. The reaction was carried out in an ultrasound bath and has been monitored by thin-layer chromatography. The reaction mixture was cooled by an ice bath and was acidified with an aqueous solution of hydrochloric acid (10\%). The precipitate was filtered off and washed repeatedly with water. In case no precipitate was formed, the mixture was extracted with $3 \times 40 \mathrm{~mL}$ of dichloromethane or chloroform; the organic layer was collected, dried over sodium sulfate, evaporated to dryness and was recrystallized with methanol. Chalcones $\mathbf{1 i i}, \mathbf{1 i v}-\mathbf{v i}$ are referred to in the literature.

3-(3-Phenoxyphenyl)-1-(thien-2-yl)prop-2-en-1-one (1i): the modified general method was followed using 3-phenoxybenzaldehyde and 2-acetylthiophene. IR (Nujol) $\left(\mathrm{v} \mathrm{cm}^{-1}\right): 3100 \mathrm{~m}(\mathrm{Ar}-\mathrm{H}), 1650 \mathrm{~s}$ $(\mathrm{C}=\mathrm{O}), 1580 \mathrm{~m}(\mathrm{C}=\mathrm{C}) .{ }^{1} \mathrm{H}-\mathrm{NMR}\left(300 \mathrm{MHz}, \mathrm{CDCl}_{3}\right): \delta(\mathrm{ppm}) 7.03-7.44(\mathrm{~m}, 10 \mathrm{H}, 9 \times \mathrm{Ph} \mathrm{H}$, $1 \times \mathrm{COC} \underline{\mathrm{H}}=, 1 \times$ thienyl $\mathrm{H}), 7.86-7.68(\mathrm{~m}, 4 \mathrm{H}, 3 \times$ thienyl $\mathrm{H}$ and $1 \times \mathrm{CH}=) .{ }^{13} \mathrm{C}-\mathrm{NMR}(75.5 \mathrm{MHz}$, $\left.\mathrm{CDCl}_{3}\right): \delta(\mathrm{ppm}) 172.9,154.6,153.2,145.4,143.3,136.6,134.0,131.9,130.3,129.9,128.2,123.7$, 123.5, 122.3, 120.8, 119.1, 118.1, 77.4, 77.0, 76.6. Anal. C, H. $\left(\mathrm{C}_{19} \mathrm{H}_{14} \mathrm{O}_{2} \mathrm{~S}\right)$; Calc. \% C: $74.18, \mathrm{H}$ : 4.60; found \% C: 74.17, H: 4.61. 
5-[4-(Dimethylamino)phenyl]-1-phenylpenta-2,4-dien-1-one (1ii): The modified synthetic method was used. The analytical data, as well as the spectral analysis were in agreement with those given in the literature [39].

3-\{4-[(4-Bromobenzyl)oxy]phenyl\}-1-(thien-2-yl)prop-2-en-1-one (1iii): the modified general method was followed using 4-[(4-bromobenzyl)oxy]benzaldehyde and 2-acetylthiophene. IR (Nujol) $\left(\mathrm{v} \mathrm{cm}^{-1}\right)$ : 3100m (Ar-H), 1680s (C=O), 1580m (C=C). ${ }^{1} \mathrm{H}-\mathrm{NMR}\left(300 \mathrm{MHz}, \mathrm{CDCl}_{3}\right): \delta(\mathrm{ppm})$ 5.07-5.11 (br, 2H, $\left.\mathrm{OC}_{2} 2\right), 6.97-7.32(\mathrm{~m}, 6 \mathrm{H}, 4 \times \mathrm{Ph} \mathrm{H}, 1 \times \gamma$-thienyl-H, $1 \times \mathrm{H} \mathrm{COCH}=), 7.51-7.85(\mathrm{~m}, 7 \mathrm{H}, 4 \times \mathrm{Ph} \mathrm{H}$, $1 \times \beta$-thienyl-H, $1 \times \delta$-thienyl-H, $1 \times \mathrm{H} \mathrm{CH}=\mathrm{CH}) .{ }^{13} \mathrm{C}$-NMR: $\left(75.5 \mathrm{MHz}, \mathrm{CDCl}_{3}\right): \delta(\mathrm{ppm}) 180.7$, $160.6,157.7,143.7,142.2$, 135.5, 133.5, 131.8, 131.5, 130.3, 129.0, 128.5, 128.2 , 128.0, 127.3, 123.6,

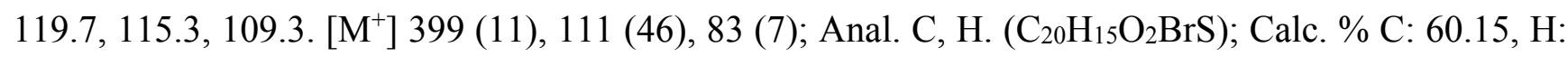
3.75; found \% C: $59.81, \mathrm{H}: 3.85$.

3-(Naphth-1-yl)-1-phenylprop-2-en-1-one (1iv): The modified synthetic method was used. The analytical data, as well as the spectral analysis were in agreement with those given in literature [40].

3-(Naphth-1-yl)-1-(4-chloro)phenylprop-2-en-1-one (1v): The modified synthetic method was used. The analytical data, as well as the spectral analysis were in agreement with those given in the literature [41].

3-(1H-Indol-5-yl)-1-phenylprop-2-en-1-one (1vi): The modified synthetic method was used. The analytical data, as well as the spectral analysis were in agreement with those given in the literature [42].

\subsubsection{General Method for the Synthesis of Pyrrolyl Derivatives}

The reaction was carried out according to a modified literature method [38]. All glassware and all used solvents were dry. Equimolar quantities of the appropriate chalcones and TosMIC were dissolved in a mixture of dry DMSO and dry diethyl ether (1:2.5). The reaction mixture was added dropwise under stirring into a suspension of sodium hydride (30 equiv. of the chalcone) in dry diethyl ether, to keep the hydrogen formation under control. The reaction was carried out in an ice bath for $24 \mathrm{~h}$. In continuation, the mixture was poured in $500 \mathrm{~mL}$ ice water. The $\mathrm{pH}$ of the solution was strongly basic. The organic phase was separated. The aquatic phase was extracted three times with ethyl acetate, dried over sodium sulfate and concentrated under vacuum. The residue was treated with cold methanol and recrystallized (cold ethyl acetate) to give the pure product.

[4-(3-Phenoxyphenyl)-1H-pyrrol-3-yl](thien-2-yl)methanone (2i): The above mentioned general method was followed using chalcone 1i. IR (Nujol) $\left(v^{-1}\right)$ : 3350m $(\mathrm{N}-\mathrm{H}), 1640 \mathrm{~s}(\mathrm{C}=\mathrm{O}), 1580 \mathrm{~m}(\mathrm{C}=\mathrm{C})$. ${ }^{1} \mathrm{H}-\mathrm{NMR}\left(300 \mathrm{MHz}, \mathrm{CDCl}_{3}\right): \delta(\mathrm{ppm})$ 8.00-8.07 (m, 1H, thienyl H), 7.58-7.62 (m, $1 \mathrm{H}, 1 \times$ thienyl H), 7.37-7.39 (m, 3H, $3 \times \mathrm{Ph} \mathrm{H}), 7.29-7.32(\mathrm{~m}, 1 \mathrm{H}, 1 \times \mathrm{Ph} \mathrm{H}), 7.03-7.27(\mathrm{~m}, 6 \mathrm{H}, 3 \times \mathrm{Ph} \mathrm{H}, 2 \times$ pyrrolyl H, $1 \times$ thienyl H), 6.84-6.99 (m, 3H, $3 \times \mathrm{Ph} \mathrm{H}) .{ }^{13} \mathrm{C}-\mathrm{NMR}\left(75.5 \mathrm{MHz}, \mathrm{CDCl}_{3}\right): \delta(\mathrm{ppm}) 165.0,133.1$, 132.6, 129.6, 129.0, 127.5, 125.0, 123.9, 122.9, 119.3, 118.6, 118.5, 117.0. Anal. C, H, N. $\left(\mathrm{C}_{21} \mathrm{H}_{15} \mathrm{NO}_{2} \mathrm{~S}\right)$; Calc. \% C: 72.39, H: 4.34, N: 4.04; found \% C: 72.22, H: 4.57, N: 3.73 .

(E)-\{4-[4-(Dimethylamino)styryl]-1H-pyrrol-3-yl\}(phenyl)methanone (2ii): The general method was followed using chalcone 1ii. IR (Nujol) $\left(v^{-1} \mathrm{~cm}^{-1}\right)$ : 3295m $(\mathrm{N}-\mathrm{H}), 1681 \mathrm{~s}(\mathrm{C}=\mathrm{O}), 1614 \mathrm{~m}(\mathrm{C}=\mathrm{C}) .{ }^{1} \mathrm{H}-\mathrm{NMR}$ 
(300 MHz, $\left.\mathrm{CDCl}_{3}\right): \delta(\mathrm{ppm})$ 7.80-7.82 (m, 2H, $\left.2 \times \mathrm{Ph} \mathrm{H}\right), 7.37-7.58(\mathrm{~m}, 5 \mathrm{H}, 5 \times \mathrm{Ph} \mathrm{H}), 7.10-7.12$ (m, 2H, $2 \times$ vinyl H, 6.75-6.89 (m, 4H, $2 \times \mathrm{Ph} \mathrm{H}, 2 \times$ pyrrolyl H), $2.96\left(\mathrm{~s}, 6 \mathrm{H}, 2 \times\right.$ methyl H). ${ }^{13} \mathrm{C}-\mathrm{NMR}$ (75.5 MHz, $\mathrm{CDCl}_{3}$ ): $\delta$ (ppm) 164.0, 131.1, 129.0, 128.0, 127.8, 127.3, 127.0, 116.0, 113.0, 22.0. Anal. C, H, N. $\left(\mathrm{C}_{21} \mathrm{H}_{20} \mathrm{~N}_{2} \mathrm{O}\right)$; Calc. \% C: 79.72, H: 6.37, N: 8.85; found \% C: 80.05, H: 6.37, N: 8.73.

(4-\{4-[(4-Bromobenzyl)oxy]phenyl\}-1H-pyrrol-3-yl)(thien-2-yl)methanone (2iii): The general method was followed using chalcone 1iii. IR (Nujol) $\left(\mathrm{v} \mathrm{cm}^{-1}\right)$ : 3500-3450br s $(\mathrm{N}-\mathrm{H}), 1710 \mathrm{~s}(\mathrm{C}=\mathrm{O}), 1580 \mathrm{~m}$ $(\mathrm{C}=\mathrm{C}) .{ }^{1} \mathrm{H}-\mathrm{NMR}\left(300 \mathrm{MHz}, \mathrm{CDCl}_{3}\right): \delta(\mathrm{ppm})$ 8.51-8.53 (br, $1 \mathrm{H}, 1 \times$ thienyl $\left.\mathrm{H}\right), 7.58-7.68(\mathrm{~m}, 3 \mathrm{H}$, $2 \times \mathrm{Ph} \mathrm{H}, 1 \times$ thienyl H), 7.49-7.52 (m, 2H, $2 \times \mathrm{Ph} \mathrm{H}), 7.29-7.40(\mathrm{~m}, 3 \mathrm{H}, 2 \times \mathrm{Ph} \mathrm{H}, 1 \times$ thienyl $\mathrm{H})$, 7.07-7.11 (br, $1 \mathrm{H}, 1 \times$ pyrrolyl $\mathrm{H}), 6.88-7.05(\mathrm{~m}, 4 \mathrm{H}, 3 \times \mathrm{Ph} \mathrm{H}, 1 \times$ pyrrolyl $\mathrm{H}), 5.00(\mathrm{~s}, 2 \mathrm{H}$, $\left.2 \times \mathrm{CH}_{2} \mathrm{O}\right) .{ }^{13} \mathrm{C}-\mathrm{NMR}\left(75.5 \mathrm{MHz}, \mathrm{CDCl}_{3}\right): \delta(\mathrm{ppm})$ 183.0, 133.0, 132.0, 131.0, 130.0, 129.0, 127.0, 125.0, 118.0, 111.0, 77.0. Anal. C, H, N. $\left(\mathrm{C}_{22} \mathrm{H}_{16} \mathrm{BrNO}_{2} \mathrm{~S}\right)$; Calc. \% C: 60.28, H: 3.68, N: 3.19; found $\%$ C: $60.15, \mathrm{H}: 3.93, \mathrm{~N}: 3.10$.

[4-(Naphth-1-yl)-1H-pyrrol-3-yl](phenyl)methanone (2iv): The general method was followed using chalcone 1iv. IR (Nujol) $\left(v \mathrm{~cm}^{-1}\right)$ : 3450s $(\mathrm{N}-\mathrm{H}), 1680 \mathrm{~s}(\mathrm{C}=\mathrm{O}), 1620 \mathrm{~m}(\mathrm{C}=\mathrm{C}) .{ }^{1} \mathrm{H}-\mathrm{NMR}(300 \mathrm{MHz}$, $\left.\mathrm{CDCl}_{3} / \mathrm{DMSO}-d_{6}\right): \delta(\mathrm{ppm}) 11.4(\mathrm{~s}, 1 \mathrm{H}, 1 \times$ pyrrolyl H), 8.93-9.10 (m, 2H, $2 \times$ naphthyl H), 8.06-8.26 $(\mathrm{m}, 3 \mathrm{H}, 3 \times$ naphthyl H), 7.90-7.93 (m, 2H, $2 \times \mathrm{Ph} \mathrm{H}), 7.79-7.81(\mathrm{~m}, 1 \mathrm{H}, 1 \times \mathrm{Ph} \mathrm{H}), 7.69-7.75$ $(\mathrm{m}, 2 \mathrm{H}, 2 \times \mathrm{Ph} \mathrm{H}), 7.49-7.59(\mathrm{~m}, 2 \mathrm{H}, 2 \times$ naphthyl H), 7.13-7.21 (br, 1H, $1 \times$ pyrrolyl H), 6.90-7.02 $\left(\mathrm{m}, 1 \mathrm{H}, 1 \times\right.$ pyrrolyl H). ${ }^{13} \mathrm{C}-\mathrm{NMR}\left(75.5 \mathrm{MHz}, \mathrm{CDCl}_{3} / \mathrm{DMSO}-d_{6}\right): \delta(\mathrm{ppm}) 173.0,130.5,128.0,127.3$, 127.2, 126.8, 126.4, 126.0, 125.7, 125.0, 124.7, 124.6, 119.7. Anal. C, H, N. (C21H15NO); Calc. \% C: 75.22, H: 4.32, N: 4.62; found \% C: 75.49, H: 4.63, N: 4.58.

(4-Chlorophenyl)[4-(naphth-1-yl)-1H-pyrrol-3-yl]methanone (2v): The general method was followed using chalcone 1v. IR (Nujol) $\left(v^{-1} \mathrm{~cm}^{-1}\right)$ : 3200w $(\mathrm{N}-\mathrm{H}), 3090 \mathrm{~m}(\mathrm{Ar}-\mathrm{H}), 1700 \mathrm{~s}(\mathrm{C}=\mathrm{O}) .{ }^{1} \mathrm{H}-\mathrm{NMR}$ (300 MHz, $\left.\mathrm{CDCl}_{3}\right): \delta(\mathrm{ppm})$ 8.76-8.96 (m, 2H, $2 \times$ naphthyl H), 8.22-8.28 (m, 1H, $1 \times$ naphthyl H), 8.06-8.10 (br, 1H, $1 \times$ naphthyl H), 7.86-7.96 (m, 3H, $2 \times \mathrm{Ph} \mathrm{H}, 1 \times$ naphthyl H), 7.6-7.53 (m, 4H, $2 \times \mathrm{Ph} \mathrm{H}, 2 \times$ naphthyl H), 7.08-7.11 (m, 1H, $1 \times$ pyrrolyl H), 6.95-6.99 $(\mathrm{m}, 1 \mathrm{H}, 1 \times$ pyrrolyl $\mathrm{H})$. ${ }^{13} \mathrm{C}-\mathrm{NMR}\left(75.5 \mathrm{MHz}, \mathrm{CDCl}_{3}\right): \delta$ (ppm) 174.0, 145.0, 141.6, 128.0, 127.0, 124.8, 122.8, 112.0, 107.4, 104.7, 100.4. Anal. C, H, N. $\left(\mathrm{C}_{21} \mathrm{H}_{14} \mathrm{ClNO}\right)$; Calc. \% C: 74.64, H: 3.96, N: 4.58; found \% C: 74.82, H: 4.08, N: 4.19 .

[4-(1H-Indol-5-yl)-1H-pyrrol-3-yl](phenyl)methanone (2vi): The general method was followed using chalcone 1vi. IR (Nujol) $\left(v_{\mathrm{cm}}^{-1}\right)$ : 3200m $(\mathrm{N}-\mathrm{H}), 1710 \mathrm{~s}(\mathrm{C}=\mathrm{O}) .{ }^{1} \mathrm{H}-\mathrm{NMR}\left(300 \mathrm{MHz}, \mathrm{DMSO}-d_{6}\right)$ : $\delta(\mathrm{ppm}) 10.97(\mathrm{~s}, 1 \mathrm{H}, 1 \times$ indolyl H), $10.22(\mathrm{~s}, 1 \mathrm{H}, 1 \times$ pyrrolyl H), 7.99-8.03 (br s, $1 \mathrm{H}, 1 \times$ indolyl H), 7.56-7.73 (m, 7H, $7 \times$ indolyl/Ph H), 7.06-7.24 (m, 3H, $2 \times$ pyrrolyl H, $1 \times$ indolyl H), 6.80-6.81 (br s, $1 \mathrm{H}, 1 \times$ indolyl H). ${ }^{13} \mathrm{C}-\mathrm{NMR}\left(75.5 \mathrm{MHz}, \mathrm{DMSO}-d_{6}\right): \delta(\mathrm{ppm}) 192.0,142.0,135.0,131.0,129.0$, 128.0, 127.0, 126.0, 125.0, 124.0, 122.0, 120.0, 117.0, 114.0, 110.0. Anal. C, H, N. $\left(\mathrm{C}_{19} \mathrm{H}_{14} \mathrm{~N}_{2} \mathrm{O}\right)$; Calc. \% C: 79.70, H: 4.93, N: 4.89; found \%: C: 79.73, H: 5.19, N: 4.85. 


\subsection{Physicochemical Studies}

Reverse-phase thin layer chromatography (RPTLC) was used for the determination of $\mathrm{R}_{\mathrm{M}}$ values. Silica gel plates were saturated with $5 \% v / v$ liquid paraffin in petroleum ether, and the mobile phase was methanol/water $(75 / 25 \mathrm{v} / \mathrm{v})$ with the addition of ammonia drops. Spots were detected under UV light. $\mathrm{R}_{\mathrm{M}}$ values were determined by the corresponding $\mathrm{R}_{\mathrm{f}}$ values (from five measurements for each compound) using the equation [43]:

$$
\mathrm{R}_{\mathrm{M}}=\log \left[\left(1 / \mathrm{R}_{\mathrm{f}}\right)-1\right]
$$

Lipophilicity was theoretically calculated as Clog $P$ values using the program of Biobyte Corporation [45]. For the calculation of physicochemical properties of the pyrrolyl derivatives, the Spartan program v.5.1.3 (Wavefunction Inc.) was used. Briefly, for each compound: (1) the structure was optimized with the quantum mechanics semi-empirical method AM1 (Austin Model 1); and (2) conformers were randomly reproduced with the Monte Carlo method by selecting all possible bonds that could rotate and by applying the dynamic field of molecular mechanics, Merck (MMFF94). Calculations were performed on the conformer with the minimum energy using quantum mechanics methods in level 6-31G* (and for compounds bearing bromium: 3-21G*) and semi-empirical in level AM1-SM2.

The C-QSAR program [45] was also used for the calculation of the values of overall molar refractivity (CMR) and of the molar refractivity of substituents (MR).

\subsection{Biological Assays}

For the in vitro biological assays, the tested compounds, as stock solutions (10 mM), were dissolved in DMSO. Final solutions of several concentrations were prepared for the assays given below. The results were the mean of at least two different experiments, and the standard deviation did not exceed $10 \%$.

\subsubsection{Biological Assays in Vitro}

Interaction with the Stable Free Radical 2,2-Diphenyl-1-picrylhydrazyl

To a solution of DPPH in absolute ethanol (50 $\mu \mathrm{M}$ final concentration), the appropriate volume of the compounds (final concentrations of 100 and $1000 \mu \mathrm{M}$ ) dissolved in DMSO was added. The absorbance was measured at $517 \mathrm{~nm}$ after 20 and $60 \mathrm{~min}$ at room temperature [52].

\section{Superoxide Radical Scavenging Activity}

The superoxide anion radicals were produced non-enzymatically by mixing phenazine methosulfate (PMS) with NADH and air-oxygen. The production of superoxide radicals was estimated with the nitroblue-tetrazolium (NBT) method with $3 \mu \mathrm{M}$ PMS, $78 \mu \mathrm{M}$ NADH and $25 \mu \mathrm{M}$ NBT in $19 \mu \mathrm{M}$ phosphate buffer $\mathrm{pH}$ 7.4. The absorbance was measured at $560 \mathrm{~nm}$ at room temperature. The tested compounds were added in the mixture 2 min before the addition of NADH [52]. 
Inhibition of Heme-Dependent Lipid Peroxidation of Linoleic Acid

Firstly, $0.4 \mathrm{~mL}$ of heme $(50 \mu \mathrm{M}), 0.25 \mathrm{~mL}$ of sodium linoleate $(400 \mu \mathrm{M}), 0.1 \mathrm{~mL}$ of the solutions of the tested compounds (concentrations varying from $10-100 \mu \mathrm{M}$ in DMSO) and $0.25 \mathrm{~mL}$ of $\mathrm{H}_{2} \mathrm{O}_{2}(500 \mu \mathrm{M})$ were incubated for $10 \mathrm{~min}$ in $37{ }^{\circ} \mathrm{C}$ in a phosphate buffer $\left(\mathrm{KH}_{2} \mathrm{PO}_{4}-\mathrm{KOH} 50 \mathrm{mM}\right.$, pH 7.4). The peroxidation products were identified with the reaction of thiobarbituric acid, by adding successively $0.5 \mathrm{~mL}$ of $40 \%$ trichloroacetic acid (TCA) and $0.5 \mathrm{~mL}$ of $2 \%$ of thiobarbituric acid (TBA) [52]. The addition was followed by stirring and heating at $90{ }^{\circ} \mathrm{C}$ for $20 \mathrm{~min}$, and then, $1 \mathrm{~mL}$ of acetic acid and $1 \mathrm{~mL}$ of chloroform were added and the absorbance measured at $535 \mathrm{~nm}$. IC 50 values were determined.

Inhibition of Soybean Lipoxygenase

The tested compounds were dissolved in DMSO, and the final concentration was $100 \mu \mathrm{M}$. The compounds were incubated at room temperature with sodium linoleate as a substrate $(0.1 \mathrm{~mL})$ in a buffer solution of Tris: $\mathrm{HCl}(\mathrm{pH} \mathrm{9.00)}$ and $0.2 \mathrm{~mL}$ of a solution of soybean lipoxygenase [52]. The conversion of linoleic acid into 13-hydroperoxylinoleic acid was measured at $234 \mathrm{~nm}$ and was compared to the reference compound nordihydroguaiaretic acid (NDGA).

Inhibition of Cycloxygenase-2 (COX-2)

COX-2 inhibitory activity was determined by using arachidonic acid (AA) as a substrate in buffer (0.1 M Tris pH 8.5) and TMPD as a co-substrate. Ten microliters of the DMSO solution of the tested compounds (final concentration $100 \mu \mathrm{M}$ ) were added in a buffer (Tris- $\mathrm{HCl} \mathrm{pH} \mathrm{8.5),} \mathrm{followed} \mathrm{by} \mathrm{the}$ addition of $0.75 \mu \mathrm{M}$ heme, $80 \mu \mathrm{M}$ arachidonic acid, COX-2 and $128 \mu \mathrm{M}$ TMPD. The mixture was incubated for $5 \mathrm{~min}$ at $37{ }^{\circ} \mathrm{C}$, and after vigorous shaking, the absorbance was measured at $590 \mathrm{~nm}[52,53]$.

Inhibition of Interleukin-6 (IL-6) (Interleukin-6 (Mouse))

The method was based on an immunometric double antibody sandwich technique. Each well of the microwell plate was coated with a specific for mouse IL-6 rat monoclonal antibody. Tested compounds at $10 \mu \mathrm{M}$ and standards were incubated in the wells, and after rinsing, a second monoclonal antibody was added, which was conjugated with biotin and detected the captured IL-6. The recognition of double antibody sandwiches was done with HRP-conjugated streptavidin. The concentration of IL-6 was determined by measuring the enzymatic activity of HRP using the chromogenic substrate TMB (3,3',5,5'-tetramethylbenzidine). The absorbance of the reaction product was measured at $450 \mathrm{~nm}$, and the intensity of the color was directly proportional to the amount of bound HRP-streptavidin conjugate, which was proportional to the concentration of IL-6.

Inhibition of the Proteolytic Activity of Trypsin

The tested compounds (concentrations varying from $10 \mu \mathrm{M}-100 \mu \mathrm{M}$ in DMSO) were dissolved in a phosphate buffer $\left(0.1 \mathrm{M} \mathrm{K}_{2} \mathrm{HPO}_{4}-\mathrm{NaH}_{2} \mathrm{PO}_{4} \cdot 2 \mathrm{H}_{2} \mathrm{O}, \mathrm{pH}=7.6\right)$, and $0.2 \mathrm{~mL}$ of trypsin $0.075 \mathrm{mg} / \mathrm{mL}$ were added. The mixture was incubated at room temperature for $20 \mathrm{~min}$, and then, $1 \mathrm{~mL}$ of bovine 
albumin $(6 \mathrm{~g} / 100 \mathrm{~mL})$ was added. The mixture was incubated at $37{ }^{\circ} \mathrm{C}$ for $30 \mathrm{~min}$. The reaction was stopped with the addition of $1 \mathrm{~mL}$ of trichloroacetic acid $(5 \% \mathrm{w} / \mathrm{w})$ Separation of the phases followed, with measurement of the supernatants at $280 \mathrm{~nm}$ at room temperature [54]. IC50 values were determined.

\subsubsection{Biological Assay in Vivo}

Inhibition of Rat Paw Edema Induced by Carrageenan

Edema was induced in the right hind paw of Fischer 344 rats (150-200 g). In the study, both males and females were included, with the exemption of pregnant females. The animals, which have been bred in our laboratory, were housed under standard conditions and received a diet of commercial food pellets and water ad libitum during maintenance. One hour before the onset of the experiment, food and water were removed. The tested compounds (dose $0.01 \mathrm{mmol} / \mathrm{kg}$ body weight) were diluted in water with a few drops of Tween 80 , and they were administered intraperitoneally simultaneously with the intradermal injection of $0.1 \mathrm{~mL} 2 \%$ of carrageenan in water. The animals were euthanatized $3.5 \mathrm{~h}$ after the carrageenan administration. The difference between the weight of injected and uninjected paws was calculated for each animal and was compared to control animals, which were treated with water [52]. Indomethacin was used as a reference compound in $0.01 \mathrm{mmol} / \mathrm{kg}$. The results were expressed as the percent inhibition of the edema (CPE \%).

\section{Conclusions}

In the present study, six pyrrolyl derivatives were designed and synthesized using chalcones as the starting material. Lipophilicity as $\mathrm{R}_{\mathrm{M}}$ values was determined, and physicochemical properties were calculated. The biological activity of the pyrrolyl derivatives was evaluated in antioxidant and anti-inflammatory assays. Compound 2 iii was found to be a potent selective COX-1 inhibitor, and as mentioned in recent literature, such compounds could be useful in neurodegenerative diseases, including Parkinson's and Alzheimer's disease, in which the production of prostaglandins in neurons and neuroglia is increased. Compound $\mathbf{2 v}$ presented satisfactory anti-inflammatory activity, inhibiting COX-2, IL-6 and trypsin. The presence of an electron-acceptor substituent $(\mathrm{Cl})$ on the phenyl ring on $\mathrm{Ar}^{2}$ and the increase of the volume of $\mathrm{Ar}^{2}$ simultaneously improve the anti-proteolytic activity significantly. A carbonyl group into the vicinal diaryl substitution in 3,4-positions of the pyrrolyl ring was found to be the structural feature for the pharmacophore. The presented combination of biological activities of $2 \mathbf{v}$ support that this pyrrolyl derivative is a promising pleiotropic bioactive molecule. Additional studies of the physicochemical properties could lead to useful conclusions for the future design of compounds with the ability to interact with multiple biological targets. Further investigation is in progress.

\section{Acknowledgments}

We thank E. Evgenidou, Department of Chemistry, Aristotle University of Thessaloniki, for providing the MS spectra. We also thank Biobyte and A. Leo for free use of C-QSAR and support. 


\title{
Author Contributions
}

M.K. performed her MSc thesis working on this research. D.H.-L. supervised the research and contributed to the writing, design, synthesis, biological evaluation and analysis of the data. A.G. has been involved in the synthesis and biological evaluation. All authors read and approved the final manuscript.

\section{Conflicts of Interest}

The authors declare no conflict of interest.

\begin{abstract}
Abbreviations
AA: arachidonic acid; Clog $P$ : theoretically-calculated lipophilicity; CMR: calculated molar refractivity; CNS: central nervous system; COX: cyclooxygenase; CPE: carrageenan-induced paw edema; DPPH: 2,2-diphenyl-1-picrylhydrazyl; HIV: human immunodeficiency virus; HMG-CoA reductase: 3-hydroxy-3-methyl-glutaryl coenzyme A reductase; HRP-streptavidin: horseradish peroxidase-labeled streptavidin; IL-6: interleukin-6; IMA: indomethacin; LOX: lipoxygenase; LP: lipid peroxidation; LTB4: leukotriene B4; MR: molar refractivity of substituent; NADH: nicotinamide adenine dinucleotide; NBT: nitroblue-tetrazolium; NDGA: nordihydroguaiaretic acid; NSAIDs: non-steroid anti-inflammatory drugs; PMS: phenazine methosulfate; RA: reducing activity; RPTLC: reverse-phase thin layer chromatography; TBA: thiobarbituric acid; TCA: trichloroacetic acid; TMB: 3,3',5,5'-tetramethylbenzidine; TMPD: $N, N, N^{\prime}, N^{\prime}$-tetramethyl-p-phenylenediamine; TosMIC: $p$-toluenesulfonylmethyl isocyanide.
\end{abstract}

\section{References and Notes}

1. Salzano, S.; Checconi, P.; Hanschmann, E.M.; Lillig, C.H.; Bowler, L.D.; Chan, P.; Vaudry, D.; Mengozzi, M.; Coppo, L.; Sacre, S.; et al. Linkage of inflammation and oxidative stress via release of glutathionylated peroxiredoxin-2, which acts as a danger signal. Proc. Natl. Acad. Sci. USA 2014, 111, 12157-12162.

2. Pizza, V.; Agresta, A.; D’Acunto, C.W.; Festa, M.; Capasso, A. Neuroinflamm-aging and neurodegenerative diseases: An overview. CNS Neurol. Disord. Drug Targets 2011, 10, 621-634.

3. Sethi, G.; Shanmugam, M.K.; Ramachandran, L.; Kumar, A.P.; Tergaonkar, V. Multifaceted link between cancer and inflammation. Biosci. Rep. 2012, 32, 1-15.

4. Aggarwal, B.B.; Vijayalekshmi, R.V.; Sung, B. Targeting inflammatory pathways for prevention and therapy of cancer: Short-term friend, long-term foe. Clin. Cancer Res. 2009, 15, 425-430.

5. Charlier, C.; Michaux, C. Dual inhibition of cyclooxygenase-2 (COX-2) and 5-lipoxygenase (5-LOX) as a new strategy to provide safer non-steroidal anti-inflammatory drugs. Eur. J. Med. Chem. 2003, 38, 645-659.

6. Botting R.M. Mechanism of action of acetaminophen: Is there a cycloxygenase 3? Clin. Infect. Dis. 2000, 31, S202-S210.

7. Vane, J.R.; Bakhle, Y.S.; Botting, R.M. Cyclooxygenases 1 and 2. Annu. Rev. Pharmacol. Toxicol. 1998, 38, 97-120. 
8. Atukorala, I.; Hunter, D.J. Valdecoxib: The rise and fall of a COX-2 inhibitor. Expert Opin. Pharmacother. 2013, 14, 1077-1086.

9. Marwali, M.R.; Mehta, J.L. COX-2 inhibitors and cardiovascular risk. Inferences based on biology and clinical studies. Thromb. Haemost. 2006, 96, 401-406.

10. Gilroy, D.W.; Tomlinson, A.; Willoughby, D.A. Differential effects of inhibitors of cyclooxygenase (cyclooxygenase 1 and cyclooxygenase 2) in acute inflammation. Eur. J. Pharmacol. 1998, 355, 211-217.

11. Leone, S.; Ottani, A.; Bertolini, A. Dual acting anti-inflammatory drugs. Curr. Top. Med. Chem. 2007, 7, 265-275.

12. Aïd, S.; Bosetti, F. Targeting cyclooxygenases-1 and -2 in neuroinflammation: Therapeutic implications. Biochimie 2011, 93, 46-51.

13. Choi, S.H.; Aid, S.; Bosetti, F. The distinct roles of cyclooxygenase-1 and -2 in neuroinflammation: Implications for translational research. Trends Pharmacol. Sci. 2009, 30, 174-181.

14. Liedtke, A.J.; Crews, B.C.; Daniel, C.M.; Blobaum, A.L.; Kingsley, P.J.; Ghebreselasie, K.; Marnett, L.J. Cyclooxygenase-1-selective inhibitors based on the (E)-2'-des-methyl-sulindac sulfide scaffold. J. Med. Chem. 2012, 55, 2287-2300.

15. Khan, S.A.; Asiri, A.M.; Alamry, K.A.; El-Daly, S.A.; Zayed, M.A. Eco-friendly synthesis and in vitro antibacterial activities of some novel chalcones. Bioorg. Khim. 2013, 39, 353-357.

16. Łącka, I.; Konieczny, M.T.; Bułakowska, A.; Rzymowski, T.; Milewski, S. Antifungal action of the oxathiolone-fused chalcone derivative. Mycoses 2011, 54, 407-414.

17. De León, E.J.; Alcaraz, M.J.; Dominguez, J.N.; Charris, J.; Terencio, M.C. 1-(2,3,4-Trimethoxyphenyl)3-(3-(2-chloroquinolinyl))-2-propen-1-one, a chalcone with analgesic, anti-inflammatory and immunomodulatory properties. Inflamm. Res. 2003, 52, 246-257.

18. Bukhari, S.N.; Jantan, I.; Jasamai, M. Anti-inflammatory trends of 1,3-diphenyl-2-propen-1-one derivatives. Mini Rev. Med. Chem. 2013, 13, 87-94.

19. Kamal, A.; Srinivasulu, V.; Nayak, V.L.; Sathish, M.; Shankaraiah, N.; Bagul, C.; Reddy, N.V.; Rangaraj, N.; Nagesh, N. Design and synthesis of C3-pyrazole/chalcone-linked beta-carboline hybrids: Antitopoisomerase I, DNA-Interactive and apoptosis-inducing anticancer agents. ChemMedChem 2014, 9, 2084-2098.

20. Kumar, C.S.; Loh, W.S.; Ooi, C.W.; Quah, C.K.; Fun, H.K. Structural correlation of some heterocyclic chalcone analogues and evaluation of their antioxidant potential. Molecules 2013, 18, 1196-2011.

21. Luo, Y.; Song, R.; Li, Y.; Zhang, S.; Liu, Z.J.; Fu, J.; Zhu, H.L. Design, synthesis, and biological evaluation of chalcone oxime derivatives as potential immunosuppressive agents. Bioorg. Med. Chem. Lett. 2012, 22, 3039-3043.

22. Okunrobo, L.O.; Usifoh, C.O.; Uwaya, J.O. Anti-inflammatory and gastroprotective properties of some chalcones. Acta Pol. Pharm. 2006, 63, 195-199.

23. Sharma, H.; Patil, S.; Sanchez, T.W.; Neamati, N.; Schinazi, R.F.; Buolamwini, J.K. Synthesis, biological evaluation and 3D-QSAR studies of 3-keto salicylic acid chalcones and related amides as novel HIV-1 integrase inhibitors. Bioorg. Med. Chem. 2011, 19, 2030-2045. 
24. Nielsen, S.F.; Christensen, S.B.; Cruciani, G.; Kharazmi, A.; Liljefors, T. Antileishmanial chalcones: Statistical design, synthesis and three-dimensional structure-activity relationship analysis. J. Med. Chem. 1998, 41, 4819-4832.

25. Murugesan, D.; Kaiser, M.; White, K.L.; Norval, S.; Riley, J.; Wyatt, P.G.; Charman, S.A.; Read, K.D.; Yeates, C.; Gilbert, I.H. Structure-activity relationship studies of pyrrolone antimalarial agents. ChemMedChem 2013, 8, 1537-1544.

26. Mohamed, M.S.; Kamel, R.; Fatahala, S.S. Synthesis and biological evaluation of some thio containing pyrrolo[2,3- $d$ ]pyrimidine derivatives for their anti-inflammatory and anti-microbial activities. Eur. J. Med. Chem. 2010, 45, 2994-3004.

27. Kim, K.J.; Choi, M.J.; Shin, J.S.; Kim, M.; Choi, H.E.; Kang, S.M.; Jin, J.H.; Lee, K.T.; Lee, J.Y. Synthesis, biological evaluation, and docking analysis of a novel family of 1-methyl- $1 H$-pyrrole2,5-diones as highly potent and selective cyclooxygenase-2 (COX-2) inhibitors. Bioorg. Med. Chem. Lett. 2014, 24, 1958-1962.

28. Arumugam, N.; Raghunathan, R.; Almansour, A.I.; Karama, U. An efficient synthesis of highly functionalized novel chromeno[4,3-b]pyrroles and indolizino[6,7-b]indoles as potent antimicrobial and antioxidant agents. Bioorg. Med. Chem. Lett. 2012, 22, 1375-1379.

29. Wang, Y.; Lu, H.; Zhu, Q.; Jiang, S.; Liao, Y. Structure-based design, synthesis and biological evaluation of new $N$-carboxyphenylpyrrole derivatives as HIV fusion inhibitors targeting gp41. Bioorg. Med. Chem. Lett. 2010, 20, 189-192.

30. Xie, L.; Xiao, Y.; Wang, F.; Xu, Y.; Qian, X.; Zhang, R.; Cui, J.; Liu, J. Novel acenaphtho [1,2-b]pyrrole-carboxylic acid family: synthesis, cytotoxicity, DNA-binding and cell cycle evaluation. Bioorg. Med. Chem. 2009, 17, 7615-7621.

31. Caruso, M.; Valsasina, B.; Ballinari, D.; Bertrand, J.; Brasca, M.G.; Caldarelli, M.; Cappella, P.; Fiorentini, F.; Gianellini, L.M.; Scolaro, A.; et al. 5-(2-amino-pyrimidin-4-yl)-1H-pyrrole and 2-(2-amino-pyrimidin-4-yl)-1,5,6,7-tetrahydro-pyrrolo[3,2-c]pyridin-4-one derivatives as new classes of selective and orally available Polo-like kinase 1 inhibitors. Bioorg. Med. Chem. Lett. 2012, 22, 96-101.

32. Weagle, G.; Gupta, A.; Bérubé, G.; Chapados, C. Evaluation of in vivo biological activities of tetrapyrrole ethanolamides as novel anticancer agents. J. Photochem. Photobiol. B. 2010, 100, 44-50.

33. Ji, X.; Su, M.; Wang, J.; Deng, G.; Deng, S.; Li, Z.; Tang, C.; Li, J.; Li, J.; Zhao, L.; Jiang, H.; Liu, H. Design, synthesis and biological evaluation of hetero-aromatic moieties substituted pyrrole-2-carbonitrile derivatives as dipeptidyl peptidase IV inhibitors. Eur. J. Med. Chem. 2014, $75,111-122$.

34. Nishida, H.; Hasuoka, A.; Arikawa, Y.; Kurasawa, O.; Hirase, K.; Inatomi, N.; Hori, Y.; Sato, F.; Tarui, N.; Imanishi, A.; et al. Discovery, synthesis, and biological evaluation of novel pyrrole derivatives as highly selective potassium-competitive acid blockers. Bioorg. Med. Chem. 2012, 20, 3925-3938.

35. Bratton, L.D.; Auerbach, B.; Choi, C.; Dillon, L.; Hanselman, J.C.; Larsen, S.D.; Lu, G.; Olsen, K.; Pfefferkorn, J.A.; Robertson, A.; et al. Discovery of pyrrole-based hepatoselective ligands as potent inhibitors of HMG-CoA reductase. Bioorg. Med. Chem. 2007, 15, 5576-5589. 
36. Dannhardt, G.; Kiefer, W.; Krämer, G.; Maehrlein, S.; Nowe, U.; Fiebich, B. The pyrrole moiety as a template for COX-1/COX-2 inhibitors. Eur. J. Med. Chem. 2000, 35, 499-510.

37. Kouskoura, M.; Hadjipavlou-Litina, D.; Giakoumakou, M. Synthesis and AntiInflammatory Activity of Chalcones and Related Mannich Bases. Med. Chem. 2008, 4, 586-596.

38. Artico, M.; Di Santo, R.; Costi, R.; Massa, S.; Retico, A.; Artico, M.; Apuzzo, G.; Simonetti, G.; Strippoli, V. Antifungal agents. 9. 3-Aryl-4-[ $\alpha-(1 H$-imidazol-1-yl)arylmethyl]pyrroles: A new class of potent anti-Candida agents. J. Med. Chem. 1995, 38, 4223-4233.

39. Jones, J.E. Supersensitization of Photographic Emulsions. US Patent 2852385 A, 16 September 1958.

40. Chiaradia, L.D.; Mascarello, A.; Purificação, M.; Vernal, J.; Cordeiro, M.N.; Zenteno, M.E.; Villarino, A.; Nunes, R.J.; Yunes, R.A.; Terenzi, H. Synthetic chalcones as efficient inhibitors of Mycobacterium tuberculosis protein tyrosine phosphatase PtpA. Bioorg. Med. Chem. Lett. 2008, $18,6227-6230$.

41. Stroba, A.; Schaeffer, F.; Hindie, V.; Lopez-Garcia, L.; Adrian, I.; Fröhner, W.; Hartman, R.W.; Biondi, R.M.; Engel, M. 3,5-Diphenylpent-2-enoic acids as allosteric activators of the protein kinase PDK1: Structure-activity relationships and thermodynamic characterization of binding as paradigms for PIF-binding pocket-targeting compound. J. Med. Chem. 2009, 52, 4683-4693.

42. Cocconcelli, G.; Diodato, E.; Caricasole, A.; Gaviraghi, G.; Genesio, E.; Ghiron, C.; Magnoni, L.; Pecchioli, E.; Plazzi, P.V.; Terstappen, G.C. Aryl azoles with neuroprotective activity-parallel synthesis and attempts at target identification. Bioorg. Med. Chem. 2008, 16, 2043-2052.

43. Rekker, R. Hydrophobic Fragmental Constant; Elsevier Scientific Co.: Amsterdam, The Netherlands, 1977; Volume 1, p. 19.

44. Hansch, C.; Leo, A.J. Exploring QSAR Fundamentals and Applications in Chemistry and Biolorgy; Heller, S.R., Ed.; ACS Professional Reference Book: Washington, DC, USA, 1995; Volume I, pp. 279-280.

45. BioByte Corporation, C-QSAR database, 201 W Fourth str. Suite \# 204, Claremont, CA 91711-4707, USA.

46. Flohe, L.; Beckman, R.; Giertz, H.; Loschen, G. Oxygen-centered free radicals as mediators of inflammation. In Oxidative Stress; Sies, H., Ed.; Academic Press: London, UK, 1985; pp. 403-435.

47. Niki, E. Do antioxidants impair signaling by reactive oxygen species and lipid oxidation products? FEBS Lett. 2012, 586, 3767-3770.

48. Evans, J.P.; Cecchini, R.; Halliwell, B. Oxidative damage to lipids and alpha 1-antiproteinase by phenylbutazone in the presence of haem proteins: Protection by ascorbic acid. Biochem. Pharmacol. 1992, 44, 981-984.

49. Crooks, S.W.; Stockley, R.A. Leukotriene B4. Int. J. Biochem. Cell. Biol. 1998, 30, 173-178.

50. Peperidou, A.; Kapoukranidou, D.; Kontogiorgis, C.; Hadjipavlou-Litina, D. Multitarget Molecular Hybrids of Cinnamic Acids. Molecules 2014, 19, 20197-20226.

51. Demopoulos, V.J.; Rekka, E. Isomeric benzoylpyrroloacetic acids: Some structural aspects for aldose reductase inhibitory and anti-inflammatory activities. J. Pharm. Sci. 1995, 84, 79-82.

52. Pontiki, E.; Hadjipavlou-Litina, D. Antioxidant and anti-inflammatory activity of aryl-acetic and hydroxamic acids as novel lipoxygenase inhibitors. Med. Chem. 2006, 2, 251-264.

53. Kulmacz, R.J.; Lands, W.E.M. Requirements for hydroperoxide by the cyclooxygenase and peroxidase activities of prostaglandin H synthase. Prostaglandins 1983, 25, 531-540. 
54. Michaelidou, A.; Hadjipavlou-Litina, D.; Matsini, I.; Tsitsogianni. E. Heterocyclic aryl(phenyl)acetic acid and aryl acetohydroxamic acids as antiinflammatory-antioxidant agents and inhibitors of lipoxygenase and serine proteases. Med. Chem. 2007, 3, 439-445.

Sample Availability: Samples of the compounds $\mathbf{1 i}-\mathbf{1 v i}$ and $\mathbf{2} \mathbf{i}-\mathbf{2} \mathbf{v i}$ are available from the authors.

(C) 2015 by the authors; licensee MDPI, Basel, Switzerland. This article is an open access article distributed under the terms and conditions of the Creative Commons Attribution license (http://creativecommons.org/licenses/by/4.0/). 